\title{
Massive pulmonary embolism in pregnancy: intra- arrest thrombolysis and resuscitative hysterotomy
}

\author{
John Edward Ashbridge Taylor $\odot,{ }^{1}$ Chen Wen Ngua, ${ }^{1}$ Matthew Carwardine ${ }^{2}$
}

${ }^{1}$ Emergency Unit, University Hospital of Wales, Cardiff \& Vale University Health Board, Cardiff, UK

${ }^{2}$ Anaesthetics, Nevill Hall Hospital, Aneurin Bevan University Health Board, Abergavenny, UK

\section{Correspondence to}

Dr John Edward Ashbridge

Taylor; john.taylor34@nhs.net

Accepted 30 March 2020

Check for updates

(c) BMJ Publishing Group Limited 2020. No commercial re-use. See rights and permissions. Published by BMJ.

To cite: Taylor JEA, Ngua CW, Carwardine M. BMJ Case Rep

2020;13:e234083

doi:10.1136/bcr-2019

234083

\section{SUMMARY}

Massive pulmonary embolism (PE) is a leading cause of maternal death and may require intra-arrest thrombolysis as well as resuscitative hysterotomy. The case presented is a primigravida in her mid-30s at 28 weeks gestation. The patient presented to the emergency department after out-of-hospital cardiac arrest. Return of spontaneous circulation (ROSC) was achieved but not sustained. Episodic cardiopulmonary resuscitation with epinephrine boluses was required. Resuscitative hysterotomy was performed intra-arrest. Echocardiography revealed a dilated right heart consistent with massive PE and thrombolysis was administered. ROSC was obtained thereafter and output was sustained. Subsequent CT brain revealed irreversible hypoxic injury. Treatment was withdrawn with the support of family. Postmortem examination confirmed massive PE. Thrombolysis can restore and improve cardiovascular status in cardiac arrest caused by massive PE. Thrombolysis is not contraindicated in maternal resuscitation where resuscitative hysterotomy may also be required.

\section{BACKGROUND}

Pulmonary embolism (PE) is one of the leading causes of maternal death in the UK and developed countries. ${ }^{12} \mathrm{PE}$ has an estimated incidence of $1-1.5$ per 10000 pregnancies with a mortality of $3.5 \% .{ }^{34}$ Cardiac arrest from all causes in pregnancy is rare with an incidence of $1: 20000 .^{5}$ Interestingly, however, this is more common than sudden cardiac death in young athletes which receives much greater public attention and has an incidence of $1: 200000 .^{5-7}$

Resuscitative hysterotomy (perimortem caesarean section) is recommended in the treatment of maternal cardiac arrest beyond 20 weeks gestation. ${ }^{1}$ Systemic thrombolysis is recommended as a treatment option in maternal cardiac arrest if the aetiology is thought to be massive PE. ${ }^{8}$ However, these two interventions are rarely performed concurrently.

We present the first case in the literature of an out-of-hospital maternal cardiac arrest managed in the emergency department (ED) with both resuscitative hysterotomy and systemic thrombolysis.

\section{CASE PRESENTATION}

A primigravida in her mid-30s presented to the ED by ambulance at 28 weeks gestation following an out-of-hospital cardiac arrest. The patient had no significant past medical history but was under review by the fetal medicine team for a fetal congenital diaphragmatic hernia on antenatal ultrasound scans.

In the early hours of the day of presentation, the emergency services were called as the patient had fallen out of bed and was reportedly cyanosed. When the paramedics arrived, she had a central pulse and was conscious but non-communicative. Within several minutes, she had a seizure followed by a pulseless electrical activity cardiac arrest. Cardiopulmonary resuscitation (CPR) was commenced and epinephrine was administered as per advanced life support guidelines. During prehospital resuscitation, the patient regained cardiac output on several occasions but this was not sustained (figure 1).

The patient was transferred to hospital by road. On arrival in the ED, she was once again in cardiac arrest with CPR ongoing. The ED team continued the resuscitation and performed manual left uterine displacement. The patient was intubated and connected to a ventilator. The first rhythm check in hospital revealed an organised rhythm with a central pulse. However, as previously, this was transient, and over the next $10 \mathrm{~min}$, the patient had repeated loss of cardiac output with subsequent return of spontaneous circulation, following epinephrine and CPR.

Given the significant haemodynamic instability and the inability to sustain cardiac output, the decision was taken to perform a resuscitative hysterotomy. This was performed by the obstetric registrar in the resuscitation room. A male infant was delivered $12 \mathrm{~min}$ after the patient's arrival in the ED. The neonatal team attempted resuscitation but there was no respiratory effort or cardiac output, and the baby was confirmed deceased 30 min after delivery.

Shortly after delivery, a maternal focused cardiac ultrasound was performed, demonstrating a dilated right heart consistent with massive PE. Cardiac output was again lost and the patient was placed on a mechanical CPR device. The option of thrombolysis was discussed and the potential for significant haemorrhage was considered. Fifty milligrams of alteplase was administered and CPR was continued. After $15 \mathrm{~min}$, with the patient still in cardiac arrest, a second dose of $50 \mathrm{mg}$ alteplase was given. The next rhythm check revealed a central pulse and there were no further episodes of cardiac arrest. The cardiac ultrasound was repeated that demonstrated a reduction in the size of the right ventricle and good left ventricular contractility. 


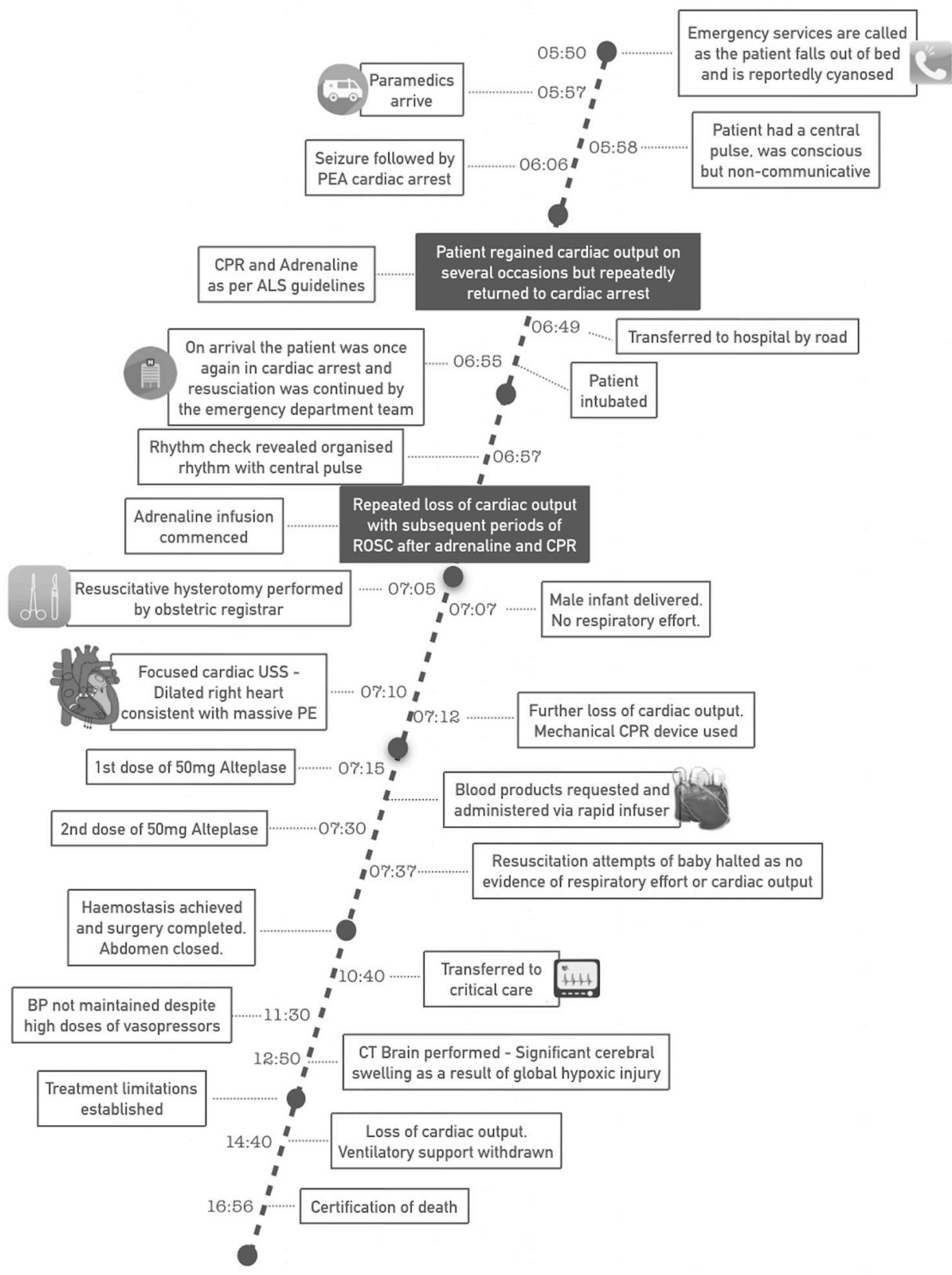

Figure 1 Case timeline. Original work by Matthew Carwardine. ALS, advanced life support; BP, blood pressure; CPR, cardiopulmonary resuscitation; $\mathrm{PE}$, pulmonary embolism; PEA, pulseless electrical activity; USS, ultrasound.

While the obstetric team achieved haemostasis, blood products were requested and administered via a rapid infuser device. An epinephrine infusion was started to support the blood pressure. The patient was transferred to the intensive care unit (ICU) where further blood products were administered.

\section{INVESTIGATIONS}

Investigations in cardiac arrest typically include an arterial or venous blood gas analysis and a focused cardiac ultrasound looking for potentially reversible causes. In this case, focused cardiac ultrasound demonstrated a massively dilated right ventricle with bowing of the septum and no pericardial effusion. These findings, along with the clinical picture and history, were sufficient to make a diagnosis of massive PE. Limitations of this investigation in cardiac arrest may include the inability to obtain adequate images, errors in interpretation and inappropriate delay or time off chest compressions.

\section{TREATMENT}

The patient was managed with concurrent CPR and resuscitative hysterotomy in the resuscitation room, shortly followed by systemic intravenous thrombolysis with Alteplase.

\section{OUTCOME AND FOLLOW-UP}

A CT brain was performed after admission to ICU. This demonstrated significant cerebral swelling as a result of a global hypoxic brain injury. The results of the scan were discussed with the family and appropriate limitations of treatment were put in place. The patient died several hours later, with her family by her side. 
The postmortem examination confirmed the presence of a deep vein thrombosis in the left internal iliac vein and the primary cause of death was recorded as massive PE.

\section{DISCUSSION}

There have been several systematic reviews of the literature to support the recommendation for resuscitative hysterotomy within 4 min of maternal cardiac arrest. ${ }^{159-11}$ However, the evidence base is limited due to the rarity of the event and the potential reporting bias of those case reports that have been published. National registries of maternal death are established in several countries, including the UK, and there have been calls for an international collaboration of data in this area to support future guideline development. ${ }^{59}$

The use of systemic thrombolysis for PE in pregnancy is well documented. ${ }^{12}$ It should be reserved for those patients with significant haemodynamic compromise (ie, massive PE) as heparin anticoagulation alone in these patients will not relieve the obstruction to the pulmonary circulation. ${ }^{8}$ There is limited evidence in the literature supporting the use of both resuscitative hysterotomy and systemic thrombolysis in maternal cardiac arrest. There is a single case report where thrombolysis was given for cardiac arrest that occurred during emergency caesarean section, which resulted in a good outcome for mother and baby. ${ }^{13}$

The Royal College of Obstetricians and Gynaecologists (UK) recommends resuscitative hysterotomy in maternal cardiac arrest beyond 20 weeks gestation if no cardiac output has been regained after $4 \mathrm{~min}$ of CPR. ${ }^{14}$ The European Society of Cardiology and the British Thoracic Society recommend systemic thrombolysis for presumed massive PE, based on clinical and echocardiographic findings. ${ }^{15} 16$

In a case where resuscitative hysterotomy is performed, the risk of maternal haemorrhage should not be considered an absolute contraindication to thrombolysis in the presence of massive PE causing cardiac arrest. ${ }^{13}$ Priority should be given to restoring the pulmonary circulation to reverse the cardiac arrest. As presented in the above case, cardiac output was only maintained after thrombolysis was administered, demonstrating the importance of treating the primary cause of cardiac arrest. Maternal haemorrhage should be anticipated and steps should be taken to mitigate this with blood product resuscitation and surgical haemostasis.

\section{Learning points}

- Thrombolysis and resuscitative hysterotomy can be performed concurrently in maternal cardiac arrest caused by pulmonary embolism, this may need to be performed in the resuscitation room and surgical haemostasis can be achieved.

- Early delivery of the fetus beyond 20 weeks gestation is vital in maternal cardiac arrest, and emergency department teams should be prepared for this procedure.

- Diagnosis of massive pulmonary embolism in cardiac arrest should be established rapidly with focused cardiac ultrasound and emergency medicine personnel should be trained in its use.
Despite the negative outcome, in this case, we believe that simultaneous resuscitative hysterotomy and systemic thrombolysis represent a reasonable treatment option in maternal cardiac arrest from PE.

Contributors JEAT, CWN and MC formed the medical team undertaking the resuscitation of the reported case. The manuscript was written jointly by JEAT, CWN and MC. The literature review was undertaken by JEAT, CWN and MC. Each author has given final approval of the version to be published and has agreed to be accountable for all aspects of the work. JEAT performed the literature search, co-authored the manuscript, edited and made corrections, wrote the cover letter and is responsible for submitting the manuscript. CWN performed the literature search and co-authored the manuscript. MC created the case timeline (figure 1), performed the literature search and co-authored the manuscript. All authors read and approved the final manuscript.

Funding The authors have not declared a specific grant for this research from any funding agency in the public, commercial or not-for-profit sectors.

Competing interests None declared.

Patient consent for publication Not required.

Provenance and peer review Not commissioned; externally peer reviewed.

\section{ORCID iD}

John Edward Ashbridge Taylor http://orcid.org/0000-0001-6147-4793

\section{REFERENCES}

1 Jeejeebhoy F, Windrim R. Management of cardiac arrest in pregnancy. Best Pract Res Clin Obstet Gynaecol 2014;28:607-18.

2 Knight M. Saving Lives, Improving Mothers' Care Surveillance of maternal deaths in the UK 2011- 13 and lessons learned to inform maternity care from the UK and Ireland Confidential Enquiries into Maternal Deaths and Morbidity 2009-1. MBRRACE-UK. National Perinatal Epidemiology Unit; 2015.

3 Truhlář A, Deakin CD, Soar J, et al. European resuscitation Council guidelines for resuscitation 2015: section 4. Cardiac arrest in special circumstances. Resuscitation 2015;95:148-201.

4 Knight M, UKOSS. Antenatal pulmonary embolism: risk factors, management and outcomes. BJOG 2008;115:453-61.

5 Jeejeebhoy FM, Zelop CM, Windrim R, et al. Management of cardiac arrest in pregnancy: a systematic review. Resuscitation 2011;82:801-9.

6 Lewis G, ed. The Confidential Enquiry into Maternal and Child Health (CEMACH). Saving Mothers' Lives: reviewing maternal deaths to make motherhood safer - 20032005. The Seventh Report on Confidential Enquiries into Maternal Deaths in the United Kingdom. London: CEMACH, 2007.

7 Maron B. Recommendations and considerations related to Preparticipation screening for cardiovascular abnormalities in competitive athletes: 2007 update. Endorsed by the American College of Cardiology Foundation: A Scientific Statement From the American Heart Association Council on Nutrition, Physical Activity, and Metabolism, 2007.

8 Thomson A, Greer I. Thromboembolic disease in pregnancy and the puerperium: acute management. Green-top guideline No. 37b. The Royal College of Obstetricians and Gynaecologists, 2015.

9 Einav S, Kaufman N, Sela HY, et al. Maternal cardiac arrest and perimortem caesarean delivery: evidence or expert-based? Resuscitation 2012;83:1191-200.

10 Katz V, Balderston K, DeFreest M, et al. Perimortem cesarean delivery: were our assumptions correct? Am J Obstet Gynecol 2005;192:1916-20.

11 Drukker L, Hants Y, Sharon E, et al. Perimortem cesarean section for maternal and feta salvage: Concise review and protocol. Acta Obstet Gynecol Scand 2014;93:965-72.

12 te Raa GD, Ribbert LSM, Snijder RJ, et al. Treatment options in massive pulmonary embolism during pregnancy; a case-report and review of literature. Thromb Res 2009:124:1-5

13 Wenk M, Pöpping DM, Hillyard S, et al. Intraoperative thrombolysis in a patient with cardiopulmonary arrest undergoing caesarean delivery. Anaesth Intensive Care 2011;39:671-4.

14 Royal College of Obstetricians and Gynaecologists. Maternal collapse in pregnancy and the puerperium- guideline. . Royal College of Obstetricians and Gynaecologists, 2011: 56. 1-24.

15 British Thoracic Society Standards of Care Committee Pulmonary Embolism Guideline Development Group. British thoracic Society guidelines for the management of suspected acute pulmonary embolism. Thorax 2003;58:470-83.

16 Konstantinides SV, Torbicki A, Agnelli G, et al. 2014 ESC guidelines on the diagnosis and management of acute pulmonary embolism. Eur Heart J 2014;35:997-1053. 


\section{Reminder of important clinical lesson}

Copyright 2020 BMJ Publishing Group. All rights reserved. For permission to reuse any of this content visit https://www.bmj.com/company/products-services/rights-and-licensing/permissions/

BMJ Case Report Fellows may re-use this article for personal use and teaching without any further permission.

Become a Fellow of BMJ Case Reports today and you can:

- Submit as many cases as you like

Enjoy fast sympathetic peer review and rapid publication of accepted articles

Access all the published articles

Re-use any of the published material for personal use and teaching without further permission

Customer Service

If you have any further queries about your subscription, please contact our customer services team on +44 (0) 2071111105 or via email at support@bmj.com.

Visit casereports.bmj.com for more articles like this and to become a Fellow 